\title{
Erratum to: Foreword of the special issue co-editors
}

\author{
Michael Browne • Rosário Macário • \\ Werner Rothengatter
}

Published online: 15 May 2012

(C) Springer-Verlag 2012

Erratum to: Logist. Res. (2012) 4:83-86

DOI 10.1007/s12159-012-0075-z

In the original publication of the article, the foreword incorrectly refers to a paper by Sönke Peters. The correct citation should be Sönke Behrends.

The correct version of the text is given below:

Sönke Behrends' paper follows similar ideas with analysing the effect of transhipment costs on the performance of intermodal line-trains.

The online version of the original article can be found under doi:10.1007/s12159-012-0075-z.

M. Browne

University of Westminster, London, UK

R. Macário

Instituto Superior Téchnico, TU Lisboa, Lisbon, Portugal

W. Rothengatter $(\bowtie)$

Karlsruhe Institute of Technology, Karlsruhe, Germany

e-mail: werner.rothengatter@kit.edu 